\title{
DEVELOPMENT AND VALIDATION OF AN HPLC-DAD ANALYTICAL METHOD TO QUANTIFY 5-METHOXYFLAVONES IN METHANOLIC EXTRACTS OF Vochysia divergens POHL CULTURED UNDER STRESS CONDITIONS
}

\author{
Letícia Pereira Pimenta ${ }^{a}$, Luís Claúdio Kellner Filhoa, Bruna Arruda Soares Parpinellib, Katia Aparecida de Siqueirab, \\ Marcos Antônio Soares ${ }^{\mathrm{b}}$, Márcio Luís Andrade e Silva ${ }^{a}$, Wilson Roberto Cunha ${ }^{\mathrm{a}}$, Patrícia Mendonça Paulettia and Ana \\ Helena Januário ${ }^{\mathrm{a}, *}$ \\ aNúcleo de Pesquisas em Ciências Exatas e Tecnológicas, Universidade de Franca, 14404-600 Franca - SP, Brasil \\ ${ }^{b}$ Laboratório de Biotecnologia e Ecologia Microbiana, Departamento de Botânica e Ecologia, Universidade Federal de Mato \\ Grosso, 78060-900 Cuiabá - MT, Brasil
}

Recebido em 25/01/2017; aceito em 15/05/2017; publicado na web em 19/07/2017

\begin{abstract}
Vochysia divergens Pohl, known as "Cambara" in Brazil, is an invasive species that is expanding throughout Pantanal in Brazil, to form mono-dominant communities. This expansion is affecting the agricultural areas that support the typical seasonal flood and drought conditions of this biome. This article describes the development and validation of an HPLC-DAD analytical method to quantify 5-methoxyflavones in methanolic extracts of greenhouse-grown $V$. divergens associated with one of two endophytic fungal species Zopfiella tetraspora $(\mathrm{Zt})$ or Melanconiella elegans $(\mathrm{Me})$ and later subjected to water stress. The developed method gave good validation parameters and was successfully applied to quantify the flavones 3 ',5-dimethoxy luteolin-7-O- $\beta$-glucopyranoside (1), 5-methoxy luteolin (2), and 3',5-dimethoxy luteolin (3) in the target extracts. Inoculation of the plant with $\mathrm{Zt}$ decreased the concentration of flavone 1 in the extract by 2.69 -fold as compared to the control. Inoculation of the plant with Zt or Me did not significantly alter the contents of flavones $\mathbf{2}$ and $\mathbf{3}$ in the extracts as compared to the control. Therefore, the aerial parts of germinated $V$. divergens plants inoculated with either $\mathrm{Zt}$ or Me responded differently in terms of the production of flavones. These results can cast light on the symbiosis between fungal microorganisms and $V$. divergens, which most likely influences the response of $V$. divergens to changes in the availability of water in Pantanal.
\end{abstract}

Keywords: Vochysia divergens; 5-methoxyflavones; HPLC-DAD quantification; water stress; endophytic fungi.

\section{INTRODUCTION}

The plant Vochysia divergens Pohl, popularly known as "Cambara", is native to the Amazon Basin. However, this plant has been spreading throughout the Brazilian Pantanal for over four decades, to form mono-dominant stands called "cambarazais". ${ }^{1,2}$ This species has invaded pastures and arable land, to cause economic problems and compromise the agricultural area available in Pantanal. ${ }^{3}$ In Pantanal, the climate is predominantly tropical with two distinct periods, the wet season (October to March) and the dry season (April to September). ${ }^{4} \mathrm{~V}$. divergens tolerates seasonal variations in hydrology and can perfectly adapt to the two seasonal periods of the Pantanal biome. ${ }^{5}$

The leaves and stems of $V$. divergens typically contain triterpenoids, flavones, phenolic compounds, tannins, and sterols. ${ }^{6,7}$ Flavones exhibit a wide range of physiological, biochemical, and ecological functions. For example, flavones are involved in UVprotection, flower coloration, interspecies interaction, allelopathy, and defense in plants. ${ }^{8-10}$

Endophytes are non-pathogenic bacteria and fungi that asymptomatically exist inside the different healthy tissues of living plants. These microorganisms are important components of plant micro-ecosystems. Host plants can benefit from the presence of endophytes: these microorganisms enhance plant growth, increase plant tolerance to biotic and abiotic stress, and influence plant metabolism. ${ }^{11-13}$ Fungal secondary metabolism can produce the same compounds as present in plants as like quercetin monoglycosides. ${ }^{14}$

To improve our understanding of the relationship between

*e-mail: anahjanuario@gmail.com
$V$. divergens and endophytic fungi, in this study we cultured $V$. divergens in a greenhouse under controlled conditions and inoculated their roots with the endophytes Zopfiella tetraspora $(\mathrm{Zt})$ and Melanconiella elegans (Me). Next, we submitted the plants to water stress for four months. After the leaf gave signs of wilting, we collected the plants and quantified 5-methoxyflavones in their methanolic extracts by a validated HPLC-DAD method.

The analytical validation of a method ensures the specificity, accuracy, and precision of an analytical test and guarantees that the analytical procedure will provide reproducible and reliable results that will be appropriate for the purposes for which they were designed. ${ }^{15}$

There are no literature reports on the development and validation of an analytical method to quantify flavones in $V$. divergens. Therefore, this investigation aimed to develop and validate an analytical procedure in terms of sensitivity, linearity, precision, recovery, robustness, limit of detection, and limit of quantitation to evaluate the contents of 5-methoxyflavones in $V$. divergens inoculated with one of two endophytes under conditions of water stress. The current gap in the knowledge of the relationship between $V$. divergens and its endophytic microbiota as well as the curious predominance of this plant in an environment under hydric stress justifies this study proposal.

\section{EXPERIMENTAL}

\section{Chemicals and reagents}

HPLC grade methanol (J.T. Baker, Phillipsburg, NJ, USA) was filtered through a Nylon 66 membrane filter measuring $0.45 \mu \mathrm{m}$ x 47 
$\mathrm{mm}$ before use. Deionized water was obtained by passing redistilled water through a Direct-Q UV3 Millipore system (Billerica, MA, USA). The flavonoids 3 ',5-dimethoxy luteolin-7- $O$ - $\beta$-glucopyranoside (1), 5-methoxy luteolin (2), and 3',5-dimethoxy luteolin (3) (Figure 1) were isolated from the hydroethanolic extract of the aerial parts of Vochysia divergens by Pimenta et al. in a previous study. ${ }^{16}$

\section{Growing of $V$. divergens plants in a greenhouse}

The surface of $V$. divergens seeds was disinfected in $70 \%$ alcohol for one minute and in sodium hypochlorite for six minutes. Then, the seeds were rinsed with autoclaved distilled water three times. Next, the seeds were germinated in trays containing sand and vermiculite and transplanted into $1 \mathrm{~L}$ pots containing the same substrate. The experiment was conducted in a greenhouse. After transplantation, the plants were irrigated with $50 \mathrm{~mL}$ of Hoagland's nutrient solution. ${ }^{17}$ After seven days, $120 \mathrm{mg} \mathrm{L}^{-1}$ aluminum with with $25 \%$ of ionic strength of Hoagland's solution was added to the plants every 12 days throughout the experiment. After four months of cultivation, the plants were subjected to water stress by completely withdrawing irrigation. When the plants gave signs of wilting, they were collected and dried in an oven at $60^{\circ} \mathrm{C}$, and the aerial parts (leaves and stems) and roots were separated.

\section{Fungal strains and inoculation of ex vitro-grown and previously established $V$. divergens plants with endophytic fungi}

For seven days, the endophytic fungi Zopfiella tetraspora (Zt), (GenBank access number KY230165, Similarity 95\%) and Melanconiella elegans (Me), (GenBank access number KJ173701, Similarity 96\%) isolated from $V$. divergens during the dry period in Pantanal (as described by Siqueira ${ }^{18}$ were activated on BDA medium. DNA was extracted according to Specht et al. ${ }^{19}$ The primers ITS5 (TCC GTA GGT GAA CCT GCG G) and ITS4 (TCC TCC GCT TAT TGA TAT GC) were used for amplification of the ITS region. ${ }^{20}$ The PCR products were purified and sequenced by the Sanger method. The ITS sequences were compared with sequences deposited in GenBank database using BLASTn (http://www.ncbi.nlm.nih.gov). The roots of the germinated plants were inoculated with micellium from one of the endophytic microorganisms, $\mathrm{Zt}$ or Me, which afforded the inoculated plants VdZt and VdMe, respectively. The roots of the control plant, $V$. divergens $(\mathrm{Vdc})$, were inoculated with sterile BDA medium.

\section{Preparation of the crude extract of $V$. divergens}

The powder of the aerial parts $(100 \mathrm{mg})$ of $\mathrm{VdZt}, \mathrm{VdMe}$, and Vdc were extracted with $5 \mathrm{~mL}$ of methanol (J.T. Baker, Phillipsburg, NJ, USA), subjected to ultrasound for 30 minutes, filtered through cotton, and filtered through a Nylon 66 membrane filter measuring $13 \mathrm{~mm} \times 12.20 \mu \mathrm{mol} \mathrm{L}{ }^{-1}$ before use. The samples were injected into the HPLC-DAD system in triplicate.

\section{HPLC-DAD analyses}

The HPLC analyses were conducted on a Shimadzu Prominence LC-20AD binary system equipped with a DGU-20A5 degasser, a SPD-20A series photo diode array (PDA) detector, a CBM-20A communication bus module, a SIL-20A HT autosampler, and a CTO-20A column oven. HPLC data were acquired with the aid of the LC solution software.

The chemical profile of the crude extracts were obtained on a Shimadzu Shim-pack Octadecyl silane (ODS) column (particle diameter of $5 \mu \mathrm{m}, 250 \times 4.6 \mathrm{~mm}$ ) equipped with a precolumn of the same material. The elution conditions were methanol/water/ acetic acid (5:94.9:0.1, v/v/v) gradient from 5 to $100 \%$ methanol for $30 \mathrm{~min}$, followed by elution with $100 \%$ methanol for $10 \mathrm{~min}$. The total analysis time was $60 \mathrm{~min}$, including the $3 \mathrm{~min}$ allowed for the system to return to the initial condition and the 17 min needed for equilibration. The detection wavelength was $254 \mathrm{~nm}$.

\section{Validation of the analytical method}

The HPLC-DAD analytical method was validated according to the Guide for validation of analytical and bioanalytical methods published by the National Health Surveillance Agency (ANVISA) RE Resolution 899 of 29/05/2003 and RDC 27/2012. . $^{2122}$ The flavone 3', 5-dimethoxy luteolin was used as standard during the validation. The extracts VdMe and Vdc were used for the validation.

\section{Linearity}

The flavone 3', 5-dimethoxy luteolin was dissolved in HPLC grade methanol, to obtain a stock solution with concentration of $1.0 \mathrm{mg} \mathrm{mL}^{-1}$. The stock solution was diluted, to give eight solutions with concentrations ranging from 0.5 to $0.0008 \mathrm{mg} \mathrm{mL}^{-1}$; each diluted solution was analyzed in triplicate. Linear least square regression of the peak areas as a function of the concentration of the compound in micrograms per milliliter helped to determine the correlation coefficients. The equation parameters (slope and intercept) of each standard curve were used to obtain the concentrations of the samples.

\section{Selectivity}

To check the selectivity of the method, a diode array detector (DAD) was used to identify the standard and to verify the peak purity during the analytical run of the extracts. The retention time of the standard was used to identify the analytical chromatographic profile.

\section{Precision}

The precision of the method was evaluated by repeatability (intrarun precision). To this end, the methanol extracts of $V$. divergens were injected in triplicate, the values of the areas of the chromatographic peaks were registered, and the relative standard deviation (RSD) of the tests was determined by calculating the standard deviation from the average and multiplying the result by 100 .

\section{Accuracy}

Recovery was assessed by using the extracts of $V$. divergens with concentration of $0.02 \mathrm{~g} \mathrm{~mL}^{-1}$. Three methanolic extract solutions were prepared, and $10 \mu \mathrm{L}$ of a $0.1 \mu \mathrm{g} \mu \mathrm{L}^{-1}$ solution of the standard was added to each solution. The concentration peak areas of each solution were determined in triplicate, and the recovery percentages were calculated.

\section{Robustness}

Robustness was evaluated by varying three analytical parameters: temperature $\left(40{ }^{\circ} \mathrm{C}\right.$ or $\left.35{ }^{\circ} \mathrm{C}\right)$, mobile phase (chemical modifier $0.1 \%$ acetic acid or $0.2 \%$ formic acid), and flow $\left(1 \mathrm{~mL} \mathrm{~min} \mathrm{~m}^{-1}\right.$ or $\left.0.9 \mathrm{~mL} \mathrm{~min}^{-1}\right)$.

\section{Limits of detection and quantification}

The limits of detection (LOD) and quantitation (LOQ) were calculated on the basis of the calibration curve, by dividing the standard deviation of the calibration curve by its slope multiplied by 3.0 and 10.0 , respectively. Ten replicates were used for the calculations. 


\section{RESULTS AND DISCUSSION}

Figure 2 depicts the analysis of the methanolic extract of the aerial parts of $V$. divergens by HPLC-DAD and reveals the presence of flavonoids 1 (Retention time - Rt $19.23 \mathrm{~min}$ ); 2 (Rt $22.14 \mathrm{~min}$ ) and 3 (Rt $23.84 \mathrm{~min}$ ) in the extract (Figure 1) by comparison of Rt, UV spectra with authentic standards obtained and identified from in natura $V$. divergens by our research group in previous studies. ${ }^{16}$ The major peak, with Rt 12.670 min, was attributed to the tannin galloyl HHDP-glucose. Flavone 3 was used as external standard to develop and to validate the chromatographic method for the qualitative and quantitative analysis of the analytes present in $V$. divergens. 5-methoxyflavones are known for their biological activities, and they have attracted the interest of some research groups in the synthesis of this skeleton. ${ }^{23,24}$ The in vitro antischistosomal activities of 5-methoxylated flavones from $V$. divergens have been evaluated. ${ }^{16}$

\section{Validation of the HPLC-DAD method}

The validation of analytical methods ensures the reliability of a production process, of new equipment, and even of the analytical methodology, especially when the quality of the manufactured product is one of the main reasons why a company exists. Selection of an appropriate analytical methodology is paramount to the quality control of an active substance or the dosage form. ${ }^{25,26}$

\section{Selectivity}

The selectivity of the method was confirmed by using the analytical software PDA for standards and for each of the tested extracts. UV spectral analysis (Figure 3) showed that no other substances (interferences) significantly contributed to the absorbance at the monitored wavelengths.<smiles>COc1cc(-c2cc(=O)c3c(OC)cc(OC4OCC(O)C(O)C(O)C4O)cc3o2)ccc1O</smiles>

1<smiles>COc1cc(O)cc2oc(-c3ccc(O)c(O)c3)cc(=O)c12</smiles>

2<smiles>COc1cc(-c2cc(=O)c3c(OC)cc(O)cc3o2)ccc1O</smiles>

3

Figure 1. Structure of the flavonoid standards 3',5-dimethoxy luteolin-7-O- $\beta$-glucopyranoside (1), 5-methoxy luteolin (2), and 3',5-dimethoxy luteolin (3) isolated from $V$. divergens

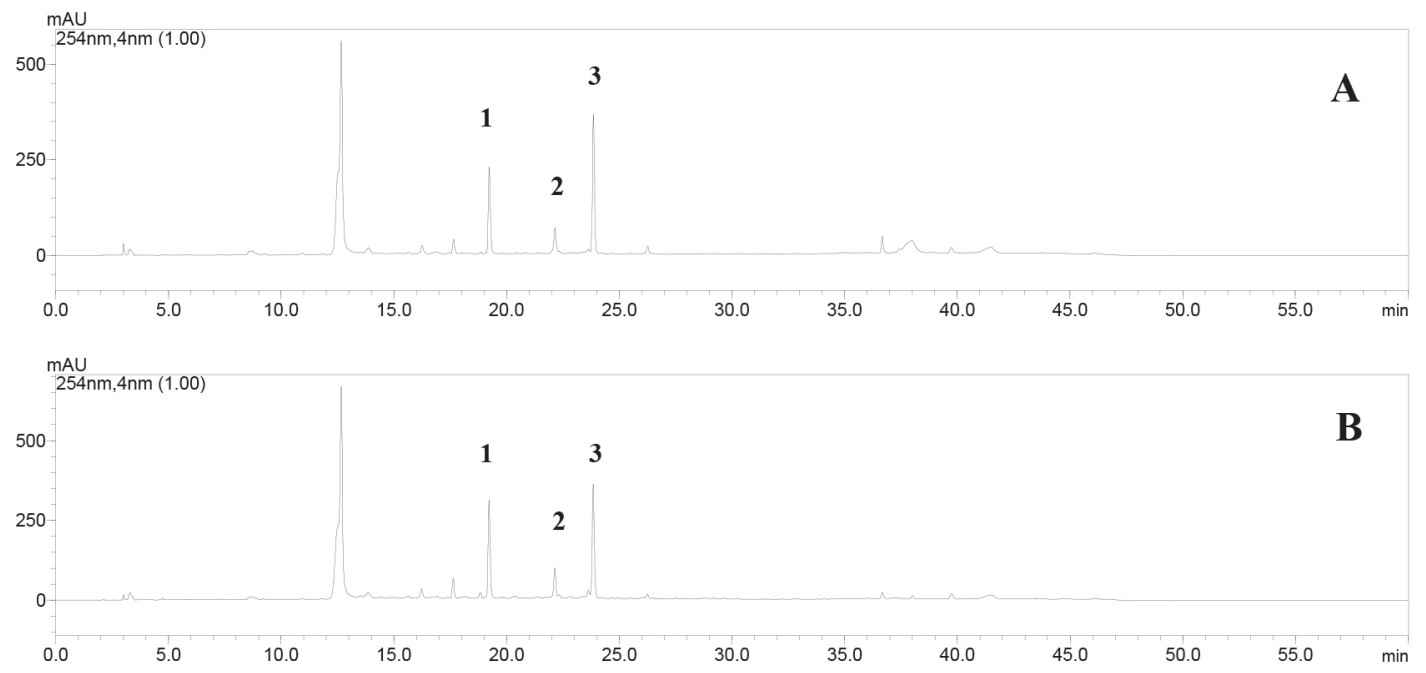

Figure 2. HPLC-DAD chromatogram of the methanolic extract of V. divergens associated with endophytic fungi. A - VdMe and control B-Vdc
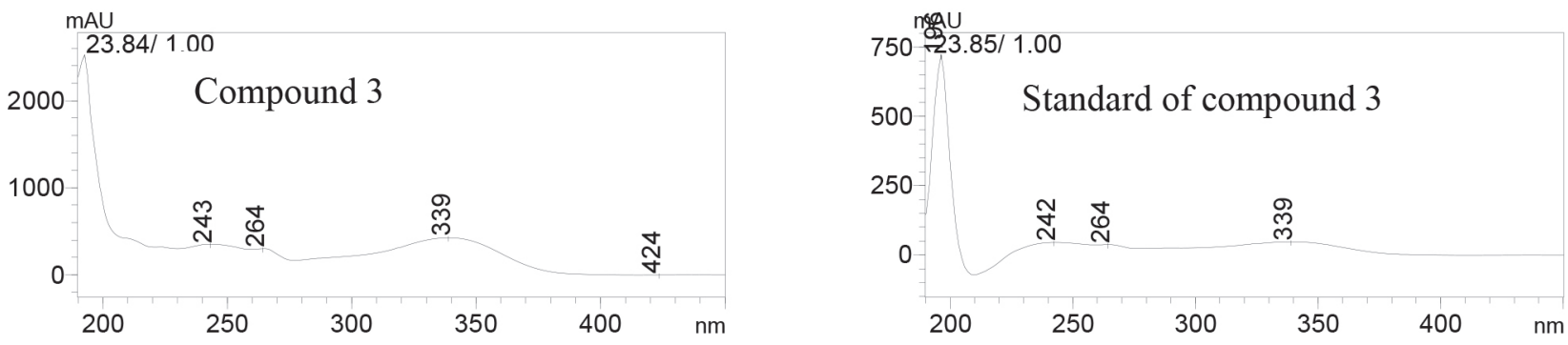

Figure 3. UV spectrum of compound 3 present in the methanolic extract of the aerial parts of $V$. divergens and spectrum of the corresponding purified compound, used as standard 


\section{Linearity and sensitivity}

The calibration curve was constructed by using flavone 3 at eight different concentrations ranging from 0.0008 to $0.5 \mathrm{mg} \mathrm{mL}^{-1}$, in triplicate. The absorption was read at $254 \mathrm{~nm}$. The linear regression equation was $y=2 \mathrm{E}+07 \mathrm{x}-30568$, with a correlation coefficient $\left(\mathrm{r}^{2}\right)$ of 0.9997. The sensitivity was expressed as LOD and LOQ, which were $0.0010 \mathrm{mg} \mathrm{mL}^{-1}$ and $0.0034 \mathrm{mg} \mathrm{mL}^{-1}$, respectively.

\section{Precision and Accuracy}

The method showed excellent reproducibility with coefficient of variation $(\mathrm{CV})$ of less than $5 \%$. The recovery results remained within the established limits, namely between $80 \%$ and $120 \%$ accuracy. Table 1 lists the results.

Table 1. Precision and accuracy results for the tested extracts

\begin{tabular}{ccc}
\hline Extracts & Precision $(\mathrm{CV} \%)$ & Accuracy $(\%)$ \\
\hline VdMe & 2.4 & 98.7 \\
Vdc & 3.8 & 97.6 \\
\hline
\end{tabular}

\section{Robustness}

The results presented in Table 2 demonstrated that $\mathrm{CV}$ was below $5 \%$ for the $\mathrm{VdMe}$ and the $\mathrm{Vdc}$ extracts upon changes in selected parameters. Therefore, the method had inherent strength and kept its response amid changes in the analyzed environment.

\section{Analysis of the methanolic extracts of VdZt, VdMe, and Vdc}

The validated method was used to quantify flavones $\mathbf{1}, \mathbf{2}$, and 3. Table 3 summarizes the results concerning the quantification of flavones in the methanolic extract of the aerial parts of $V$. divergens from the calibration curve constructed for the HPLC-DAD method. All the samples, VdZt, VdMe and Vdc, contained the three flavones 1-3.

The content of flavone 1 in VdZt $\left(2.23 \pm 0.39 \mathrm{mg} \mathrm{g}^{-1}\right.$ dry weight (DW) ) and VdMe (4.55 $\left.\pm 0.41 \mathrm{mg} \mathrm{g}^{-1} \mathrm{DW}\right)$ decreased (2.69-fold and 1.32-fold, respectively) as compared to its content in the control sample Vdc, which presented the highest concentration of this metabolite $\left(6.01 \pm 1.39 \mathrm{mg} \mathrm{g}^{-1} \mathrm{DW}\right)$. The contents of flavones $\mathbf{2}$ and 3 were practically the same in the three samples. As for the contents of flavones 1, 2, and $\mathbf{3}$ in the sample $\mathrm{VdZt}$, the content of flavone $\mathbf{3}$ was the highest: $5.78 \pm 0.79 \mathrm{mg} \mathrm{g}^{-1} \mathrm{DW}$, which was 2.59 -fold higher than the contentof flavone $\mathbf{1}\left(2.23 \pm 0.39 \mathrm{mg} \mathrm{g}^{-1} \mathrm{DW}\right)$ and 4.22 -fold higher than the content of flavone $2\left(1.37 \pm 0.15 \mathrm{mg} \mathrm{g}^{-1} \mathrm{DW}\right)$. As for the sample $\mathrm{VdMe}$, the contents of flavones $\mathbf{1}$ and $\mathbf{3}$ were practically the same $\left(4.55 \pm 0.41 \mathrm{mg} \mathrm{g}^{-1} \mathrm{DW}\right.$ and $4.37 \pm 0.73 \mathrm{mg} \mathrm{g}^{-1} \mathrm{DW}$, respectively) and higher than the content of flavone $2(1.87 \pm 0.36$ $\left.\mathrm{mg} \mathrm{g}^{-1} \mathrm{DW}\right)$. Concerning the control sample Vdc, the contents of flavones $1\left(6.01 \pm 1.39 \mathrm{mg} \mathrm{g}^{-1} \mathrm{DW}\right)$ and $\mathbf{3}\left(6.23 \pm 0.25 \mathrm{mg} \mathrm{g}^{-1} \mathrm{DW}\right)$ were also practically the same and higher than the content of flavone $2\left(1.90 \pm 0.26 \mathrm{mg} \mathrm{g}^{-1} \mathrm{DW}\right)$.

The contents of the flavonoid glucosides luteolin 7-O-glucoside and quercetin 7-O-glucoside decreased in Safflower leaves cultivated under hydric stress condition. ${ }^{27}$ In the case of Capsicum annuum associated with the endophytic fungus Penicillium resedanum LK6, flavonoids were synthesized in higher quantities as compared to the control plant. ${ }^{28}$ In another approach, Guidi and collaborators confirmed that water stress and solar irradiance affected the physiology and the concentrations of non-structural carbohydrates and phenylpropanoids in Ligustrum vulgare..$^{29}$ Yuan et al.,${ }^{30}$ observed decreased levels of endogenous gibberellic acid (GA) and increased levels of indol acetic acid (IAA) in the leaves of Scutellaria baicalensis treated under conditions of water deficit. The water deficit probably affected the accumulation of flavonoids by regulating the metabolism of hormones in S. baicalensis. ${ }^{30}$

The development of endophytic symbiosis can help plants in terms of the composition of mineral nutrients, fixation of $\mathrm{N}_{2}$, hormonal balance, physical modification of the soil, and protection of the host against biotic and abiotic stress. ${ }^{11,31}$ Beneficial plant-associated microorganisms may enhance resistance to abiotic stress among other factors, ${ }^{31}$ but understanding of the relationship between endophytic fungi and their host plants is still very limited, and many symbiotic systems can only be understood in the context of natural adversity of the host. ${ }^{32}$ Voglmayr et al. ${ }^{33}$ have described M. elegans as a new species on the basis of morphological and phylogenetic analyses. To the best of our knowledge, this is the first time this microorganism has been detected in $V$. divergens. Concerning Zopfiella tetraspora, this species has been previously isolated from soil, but this is the first report on its isolation from $V$. divergens.

The flavones 1-3 evaluated in this study bear a methoxyl group at position 5 of ring A. Flavones $\mathbf{1}$ and $\mathbf{3}$ were the flavones with the highest contents in the investigated plants, and they have the same substitution pattern in ring B. In contrast, flavones $\mathbf{2}$ and $\mathbf{3}$ have the same substitution pattern in ring A. Regarding the substitution pattern in ring $\mathrm{A}$ of the isolated flavones, only flavone $\mathbf{1}$ is glycosylated at position 7. UDP-glycosyltransferases usually glycosylate flavonoids. Studies on Withania somnifera have shown that expression of glycosyltransferases varies in different ways under biotic and abiotic

Table 2. Standard deviation of results after variations in temperature, mobile phase, and flow, attesting to the robustness of the developed method

\begin{tabular}{lcccccc}
\hline CV \% & \multicolumn{2}{c}{ Temperature } & \multicolumn{2}{c}{ Mobile phase } & \multicolumn{2}{c}{ Flow } \\
\hline Extracts & $40^{\circ} \mathrm{C}$ & $35^{\circ} \mathrm{C}$ & Formic acid & Acetic acid & $1.0 \mathrm{~mL} \mathrm{~min}^{-1}$ & $0.9 \mathrm{~mL} \mathrm{~min}^{-1}$ \\
$\mathrm{VdMe}$ & 2.4 & 1.4 & 1.9 & 1.4 & 1.5 & 2.5 \\
$\mathrm{Vdc}$ & 0.7 & 2.0 & 0.9 & 3.0 & 1.5 & 0.7 \\
\hline
\end{tabular}

Table 3. Concentration of the flavones 3',5-dimethoxy luteolin-7-O- $\beta$-glucopyranoside (1), 5-methoxy luteolin (2), and $3^{\prime}, 5$-dimethoxy luteolin (3) in extracts of $V$. divergens

\begin{tabular}{lccc}
\hline Samples & $\begin{array}{c}\text { Flavone } 1^{\mathrm{a}} \\
\left(\mathrm{mg} \mathrm{g}^{-1} \mathrm{DW}^{\mathrm{b}}\right)\end{array}$ & $\begin{array}{c}\text { Flavone 2 } \\
\left(\mathrm{mg} \mathrm{g}^{-1} \mathrm{DW}\right)\end{array}$ & $\begin{array}{c}\text { Flavone 3 } \\
\left(\mathrm{mg} \mathrm{g}^{-1} \mathrm{DW}\right)\end{array}$ \\
\hline $\mathrm{VdZt}$ & $2.23 \pm 0.39 \mathrm{Bb}^{\mathrm{c}}$ & $1.37 \pm 0.15 \mathrm{Ab}$ & $5.78 \pm 0.79 \mathrm{Aa}$ \\
$\mathrm{VdMe}$ & $4.55 \pm 0.41 \mathrm{ABa}$ & $1.87 \pm 0.36 \mathrm{Ab}$ & $4.37 \pm 0.73 \mathrm{Aa}$ \\
$\mathrm{Vdc}$ & $6.01 \pm 1.39 \mathrm{Aa}$ & $1.90 \pm 0.26 \mathrm{Ab}$ & $6.23 \pm 0.25 \mathrm{Aa}$ \\
\hline
\end{tabular}

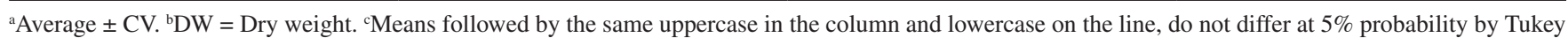
test. CV $(\%)=$ coefficient of variation \pm standard error. 
stress. ${ }^{34}$ Flavones participate in several microbe-plant interactions. In leguminous plants, flavones act as signal molecules for the establishment of symbiotic relationships between the plant and root nodulation bacteria. ${ }^{35}$

In general, 5-methoxylated flavones are rare in nature. However, polymethoxyflavones largely occur in citrus, providing the plant with resistance against microbial infections. ${ }^{36}$ Plants under stress conditions preferentially accumulate dihydroxy B-ring-substituted flavonoids, which are effective scavengers of reactive oxygen species (ROS). This is consistent with the generation of ROS being a common trait among plants that are challenged with a range of environmental stresses. $^{37}$

Analysis of the methanolic extracts of the samples VdMe and Vdc by the developed method proved to be accurate and gave recovery and robustness results within the limits set for these extracts. LOD and LOQ were $0.0010 \mathrm{mg} \mathrm{mL}^{-1}$ and $0.0034 \mathrm{mg} \mathrm{mL}^{-1}$, respectively. All the figures of merit evaluated herein afforded results that were consistent with the values recommended by the adopted analytical standards. There are no reports on the validation of an HPLC-DAD method for V. divergens; only a dereplication method by HPLC-ESI-QToF-MS/ MS has been described for Qualea species (Vochysiaceae). ${ }^{38}$

\section{CONCLUSION}

Compared to the control plant, Vochysia divergens plants inoculated with one of the endophytic fungi $\mathrm{Zt}$ or Me responded differently in terms of the production of 5-methoxyflavones in their aerial parts during water stress. Therefore, the symbiosis between the microorganism and the plant influences the response of the host to the availability of water in Pantanal. Further studies will be necessary to improve our understanding of the symbiotic relationship between $V$. divergens and its endophytes under water stress. The validated method will be important to control the quality of $V$. divergens cultured plants in further experiments because $V$. divergens is an invasive tree that forms mono-dominant communities and affects agricultural areas in Pantanal.

\section{ACKNOWLEDGEMENTS}

The authors are grateful to Fundação de Amparo a Pesquisa do Estado de São Paulo (FAPESP, Grant \# 2013/22030-9, Grant \# 2013/15774-1 and Grant \# 2016/08057-0) and Conselho Nacional de Desenvolvimento Científico e Tecnológico (CNPq) for fellowships. FAPESP (Grant \# 2011/00631-5), FAPEMAT (Grant \# 331950/2012), and INAU are also acknowledged for financial support.

\section{REFERENCES}

1. Arieira, J.; Nunes Da Cunha, C.; Oecologia Australis 2012, 16, 819.

2. Vourlitis, G. L.; Lobo, F. D. A.; Biudes, M. S.; Ortíz, C. E. R.; Nogueira, J. D. S.; Soil Sci. Soc. Am. J. 2011, 75, 1554.

3. Nunes Da Cunha, C.; Junk, W. J.; Applied Vegetation Science 2004, 7, 103.

4. Fernandes, M. I; Signor, A. C; Penha, J.; Biodiversidade no Pantanal de Poconé, $1^{\text {st }}$ ed., Centro de Pesquisas do Pantanal: Cuiabá, 2010.

5. Dalmolin A. C.; Dalmagro, H. J.; Lobo, F. De A.; Antunes Jr., M. Z.; Ortíz, C. E. R.; Vourlitis, G. L.; Photosynthetica 2013, 51, 379.

6. Hess, S. C.; Monache, F. D.; J. Braz. Chem. Soc. 1999, 10, 104.

7. Neto, F.C.; Pilon, A. C.; Silva, D. H. S.; Bolzani, V. S.; Castro-Gamboa, I.; Phytochem. Rev. 2011, 10, 413.

8. Martens, S.; Mithöfer A.; Phytochemistry 2005, 66, 2399.

9. Stochmal, A.; Oleszek, W.; J. Food. Agric. Environ. 2007, 5, 170.

10. Buer, C. S.; Imin, N.; Djordjevic, M. A.; J. Integr. Plant Biol. 2010, 52 , 198.
11. Jia, M.; Chen, L.; Xin, H. L.; Zheng, C. J.; Rahman, K.; Han, T.; Qin, L. P.; Frontiers in Microbiology 2016, 7, 906.

12. Soares, M. A.; Li, H. Y.; Bergen, M.; Silva, J. M. D.; Kowalski, K. P.; White, J. F.; Plant Soil 2016, 405, 107.

13. White, J. F.; Kingsley, K. I.; Kowalski, K. P.; Irizarry, I.; Micci, A.; Soares, M. A.; Bergen, M. S.; Plant Soil (2017), doi: 10.1016/j. jenvman.2015.08.042

14. Ebada, S. S.; Eze, P.; Okoye, F. B. C.; Esimone, C. O.; Proksch, P.; ChemistrySelect 2016, 1, 2767.

15. Silva, J. A.; Bedor, D. C. G; Sousa, C. E. M.; Santana, D. P.; Egito, E. S. T.; Rev. Cienc. Farm. Basica Apl. 2010, 31, 41.

16. Pimenta, L. P.; Kellner Filho, L. C.; Liotti, R. G.; Soares, M. A.; Aguiar, D. P.; Magalhães, L. G.; Oliveira, P. F.; Tavares, D. C.; Silva, M. L. A.; Cunha, W. R.; Pauletti, P. M.; Januário, A. H.; $A d v$. Pharmacoepidemiol. Drug Saf. 2015, 4, 47.

17. Hoagland, D. R.; Arnon, D. I.; The water culture method for growing plants without soil, $1^{\text {st }}$ ed., University of California Berkeley: Berkeley, 1950.

18. Siqueira, K. A.; Brissow, E. R.; Santos, J. L. D.; White, J. F.; Santos, F. R.; Almeida, E. G. D.; Soares, M.A.; Symbiosis 2016, 25, 1.

19. Specht, C. A.; Dirusso, C. C.; Novotny, C. P.; Ullrich, R. C.; Anal. Biochem. 1982, 119, 158.

20. White, T. J.; Bruns, T.; Lee, S.; Taylor, J. W. In PCR Protocols: A Guide to Methods and Applications, Innis, M. A.; Gelfand, D. H.; Sninsky, J. J.; White, T. J., eds.; Academic Press, Inc.: San Diego, 1990, cap. 38.

21. Brasil, Ministério da Saúde, Agência Nacional de Vigilância Sanitária (ANVISA); Resolução RE No 899, de 29/05/2003, Guia para validação de métodos analíticos e bioanalíticos.

22. Brasil, Ministério da Saúde, Agência Nacional de Vigilância Sanitária (ANVISA); Resolução RDC N ${ }^{\circ} 27$, de 17/05/2012, Dispõe sobre os requisitos mínimos para a validação de métodos bioanalíticos empregados em estudos com fins de registro e pós-registro de medicamentos.

23. Ares, J. J.; Outt, P. E.; Kakodkar, S. V.; Buss, R. C.; Geiger, J. C.; J. Org. Chem. 1993, 58, 7903.

24. Song, G. Y.; Ahn, B. Z.; Arch. Pharmacal Res. 1995, 18, 440.

25. Nascimento, G. N. L.; Pereira, K. C. F.; Nishijo, H.; Aversi-Ferreira, T. A.; Acta Scientiarum. Health Sciences 2011, 33, 153.

26. Valentini, S. R.; Sommer, W. A.; Matioli, G.; Arquivos do MUDI 2007, $11,26$.

27. Yaginuma, S.; Shiraishi, T.; Igarashi, K.; Biosci., Biotechnol., Biochem. 2003, 67, 1691.

28. Khan, A. L.; Kang, S-M.; Dhakal, K. H.; Hussain, J.; Adnan, M.; Kim, J-G.; Lee, I-J.; Sci. Hortic. 2013, 155, 1.

29. Guidi, L.; Degl'Innocenti, E.; Remorini, D.; Massai, R.; Tattini, M.; Tree Physiol. (Oxford, U. K.) 2008, 28, 873.

30. Yuan, Y.; Liu, Y.; Wu, C.; Chen, S.; Wang, Z.; Yang, Z.; Qin, S.; Huang, L.; PLoS One 2012, 7, e42946.

31. Compant, S.; Van Der Heijden, M. G.; Sessitsch, A.; FEMS Microbiol. Ecol. 2010, 73, 197.

32. Clay, K.; Poole, P.; New Phytol. 2010, 185, 1.

33. Voglmayr, H.; Rossman, A. Y.; Castlebury, L. A.; Jaklitsch, W. M.; Fungal Diversity 2012, 57, 1.

34. Singh, S.; Vishwakarma, R. K.; Kumar, R. J.; Sonawane, P. D.; Ruby; Khan, B. M.; Appl. Biochem. Biotechnol. 2013, 170, 729.

35. Martens, S.; Mithofer, A.; Phytochemistry 2005, 66, 2399.

36. Mahoney, N. E.; Roitman, J. N.; Chan, B. C.; J. Chem. Ecol. 1989, 15, 285 .

37. Agati, G.; Azzarello, E.; Pollastri, S.; Tattini, M.; Plant Sci. 2012, 196, 67.

38. Carnevale Neto, F.; Siquitelli, C. D.; Pilon, A. C.; Silva, D. H. S.; Bolzani, V. D. S.; Castro-Gamboa, I.; J. Braz. Chem. Soc. 2013, 24, 758. 